CLINICAL STUDY

\title{
Gender dimorphism in body composition abnormalities in acromegaly: males are more affected than females
}

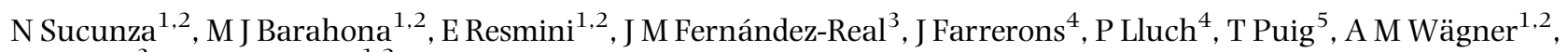 \\ W Ricart ${ }^{3}$ and S M Webb ${ }^{1,2}$ \\ ${ }^{1}$ Endocrinology Department and Centro de Investigación Biomédica en Red de Enfermedades Raras (CIBER-ER, Unidad 747), ISCIII, O8025 Barcelona, \\ Spain, ${ }^{2}$ Hospital Sant Pau, Autonomous University of Barcelona, Barcelona, Spain, ${ }^{3}$ Endocrinology Department, Institut d'Investigació Biomèdica de \\ Girona (IDIBGI) and CIBER Fisiopatología de la Obesidad y Nutrición CB06/03/010, Hospital Josep Trueta, Girona, Spain, ${ }^{4}$ Department of Internal \\ Medicine and ${ }^{5}$ Department of Epidemiology, Hospital Sant Pau, Autonomous University of Barcelona, Barcelona, Spain
}

(Correspondence should be addressed to N Sucunza who is now at Department of Endocrinology, Hospital Manacor, Carretera de Palma a Artà s/n, O7500 Manacor, Mallorca, Spain; Email: nsucunza@hmanacor.org)

\begin{abstract}
Background: Acromegaly changes body composition (BC), but long-term gender differences have not been reported.

Objective: To evaluate BC in active and controlled acromegalic patients.

Design and methods: Clinical and biochemical variables and BC (by dual-energy X-ray absorptiometry) were evaluated in 60 acromegalic patients (19 active, 41 controlled) and 105 controls, matched for age and gender.

Results: Acromegalic males $(n=24)$ had more total mass $(89 \pm 13 \mathrm{vs} 76.5 \pm 15.3 \mathrm{~kg}, P<0.001)$, lean body mass (LBM; $64.6 \pm 8.7$ vs $56.4 \pm 5.8 \mathrm{~kg}, P<0.001$ ), and bone mineral content (BMC; $2.9 \pm 0.5 \mathrm{vs}$ $2.6 \pm 0.3 \mathrm{~kg}, P<0.05)$ than controls $(n=33)$. Controlled male patients $(n=14)$ had more total mass $(89 \pm 14.7$ vs $76.5 \pm 15.3 \mathrm{~kg}, P<0.05)$ and a trend to have more LBM $(61.8 \pm 9.4 \mathrm{vs} 56.4 \pm 5.8 \mathrm{~kg}$, $P=0.065$ ) than controls. Only in active disease was a decrease in fat mass (FM) observed, compared with controlled patients and controls (males: $19.5 \pm 5.3$ vs $27 \pm 6.2$ and $25.9 \pm 4 \%, P<0.001$; females: $30.3 \pm$ 6.7 vs $37.1 \pm 5.8$ and $36.5 \pm 6.6 \%, P<0.01)$. In females, no further differences were observed. No differences in BMC were found between eugonadal and hypogonadal acromegalic patients, but in hypogonadal females, acromegaly appeared to prevent the BMC loss seen in hypogonadal postmenopausal controls. GH and IGF1 levels were negatively correlated with FM (males, $P<0.05$; females, $P<0.001$ ), but in the regression analysis $\mathrm{GH}$ was a predictor of FM only in women.

Conclusions: Control of acromegaly reverts decreased FM in both genders; only in males more total mass and a trend for more LBM persist. The anabolic effect of GH on bone reverted in cured males, but persisted in females and appeared to override the bone loss of menopause.
\end{abstract}

European Journal of Endocrinology 159 773-779

\section{Introduction}

Body composition (BC) in acromegaly has been previously evaluated with bioelectrical impedance analysis, total body potassium, total body water, and anthropometry (1-5). Dual-energy X-ray absorptiometry (DEXA), introduced more recently in the assessment of $\mathrm{BC}$, has the advantage of providing a comprehensive, non-invasive estimate of each tissue compartment. BC changes in acromegaly, namely body weight, lean body mass (LBM), and bone mineral content (BMC) increase, while fat mass (FM) is reduced (3, 6-9), but differences between genders have not been previously described. Increased body fat, and especially visceral fat, is associated with an increase in cardiovascular risk in normal population $(10,11)$ and different diseases (11-13); whether a decrease in body fat is related to changes in cardiovascular risk in acromegaly is not known. Brummer et al. (14) showed in 15 patients with acromegaly that changes in $\mathrm{BC}$ tended to be more pronounced in men than in women. This was a 1-year follow-up study, and no further reports have approached this issue or evaluated long-term changes in $\mathrm{BC}$. The primary aim of this case-control study was to investigate $\mathrm{BC}$, as assessed by DEXA, in acromegalic male and female patients, both with controlled and active disease, and to compare results with those of healthy controls matched for age and gender. In addition, possible relations between $\mathrm{BC}$ and relevant clinical and biochemical variables were investigated.

\section{Subjects and methods}

\section{Subjects}

In this case-control study, eligible cases were all 117 consecutive adult acromegalic patients diagnosed and 
treated in our center since 1982; 57 cases were excluded for the following reasons: 15 had died, 20 were presently followed at other institutions, and 22 declined to participate. The final number of cases included in this study was 60 (24 males and 36 females); 54 had undergone surgery (53 transsphenoidal and 1 craniotomy) and 3 conventional radiotherapy, as the first definitive treatment. At the time of the study, three persons were awaiting transsphenoidal surgery and were on somatostatin analog treatment. As secondary treatment, 6 were reoperated (transsphenoidally) and 22 were irradiated (19 with conventional and 3 with stereotactic radiosurgery). At study entry, GH hypersecretion persisted in 19 patients, of which 17 were treated with somatostatin analogs and 3 with pegvisomant. Disease duration was defined as years reported by the patient since symptoms appeared until cure criteria were achieved; in non-controlled patients, this period extended until study date. Disease remission was defined as the years since criteria of cure were achieved to study date.

From the blood donors' database at our hospital, 33 men and 72 women were selected as healthy controls. For each patient, blood donors matched for age, gender, and date of blood donation (the same year of the diagnosis of acromegaly) were identified. For each patient, letters were sent to four selected controls, and a phone call was made 1 week later in alphabetical order; the first controls to accept were included.

Both patients with acromegaly and healthy controls were evaluated by a single doctor (N S), who updated the clinical history and performed a physical examination, including anthropometric measurements. ATP III criteria (15) were used to define metabolic syndrome. Whole body DEXA and blood sampling (including blood glucose, total cholesterol, high-density lipoprotein (HDL) cholesterol, low-density lipoprotein (LDL) cholesterol, insulin, GH, and IGF1) were performed. Biochemical control of acromegaly was defined as GH levels $<1 \mu \mathrm{g} / \mathrm{l}$ during a $2 \mathrm{~h} 75 \mathrm{~g}$ oral glucose tolerance test (OGTT) and normal age- and sex-matched IGF1; patients who did not attain these levels were considered active. Patients presently on somatostatin analog treatment were considered active if IGF1 was above normal, without repeating an OGTT. All patients and controls gave informed consent after study approval by the hospital ethics committee.

\section{BC analysis}

Lumbar spine and whole body bone mineral density (BMD) and BC (BMC, whole and truncal FM, LBM, and total mass) were measured by DEXA scanning (DEXA, Delphi QDR 4500, Hologic, Vilvoorde, Belgium). The mean precision error (coefficient of variation) was $1 \%$. This technique measures the body components of maximum density (mineral in bone BMC) and minimum density (FM), and the remaining body mass is considered LBM (which includes muscle, visceral organs, connective tissues, etc).

\section{Biochemical measurement}

Blood samples were collected after an overnight fast. Routine serum determinations were performed by standard automated techniques: total cholesterol and triglycerides by enzymatic methods, HDL cholesterol by a direct method, and LDL cholesterol by the Friedewald formula. Serum GH was determined by a chemiluminescence system (Immulite DPC; EURO/Diagnostic Products Corporation, Llanberis, UK), which uses the hGH $80 / 505$ calibrator with a sensitivity of $0.01 \mu \mathrm{g} / \mathrm{l}$ (conversion factor for SI units, $\mu \mathrm{g} / \mathrm{l} \times 2.6=\mathrm{mIU} / \mathrm{l})$ and with intraassay coefficients of variation of $5.3-6.5 \%$. Serum IGF1 concentration was determined by IRMA (DPC Immulite 2000 chemiluminescence system) with a sensitivity of $20 \mu \mathrm{g} / \mathrm{l}$ and intra-assay imprecision of $2.6-4.3 \%$.

\section{Statistical analysis}

A descriptive analysis was performed as the first step. Data distribution was analyzed by the Kolmogorov-Smirnov test. Comparison between three groups was performed using an ANOVA, and between two groups using Student's $t$-test (Gaussian distribution) and Mann-Whitney's U-test (non-Gaussian distribution). Pearson's correlation coefficients were used to explore the association between whole body DEXA variables and anthropometric and biochemical measurements. The correlation between two variables was calculated using Spearman's rank correlation test. In order to find predictors of $\mathrm{BC}$, correlations using Spearman's rank and a stepwise, forward lineal regression analysis were performed, including $\mathrm{BC}$ variables as dependent variable, and disease duration, age, IGF1, and GH as independent variables. Data were analyzed using SPSS version 15.0 statistical package for Windows (SPSS Inc., Chicago, IL, USA), and statistical significance was set at $P<0.05$. Quantitative data were expressed as mean \pm S.D. (Gaussian distribution).

\section{Results}

\section{Comparison of acromegalic patients and controls}

Patients with acromegaly had more diabetes (23 vs $2.4 \%, P<0.001)$, hypertension $(37.7$ vs $15 \%$, $P<0.005)$, and metabolic syndrome $(25.4$ vs $5.4 \%$, $P<0.05)$ than matched controls. No differences in the prevalence of dyslipidemia (30 vs $24.7 \%$ ), obesity ( 23.4 vs $19.3 \%$ ), or smoking ( 26.2 vs $16.3 \%$ ) were observed between patients and controls. Clinical characteristics of the acromegalic patients and healthy controls are presented in Table 1. Males (but not females) with acromegaly had more total body mass $(P<0.001)$, LBM 
Table 1 Clinical characteristics and body composition in acromegalic patients and healthy controls.

\begin{tabular}{|c|c|c|c|c|}
\hline & \multicolumn{2}{|c|}{ Men } & \multicolumn{2}{|c|}{ Women } \\
\hline & Acromegalic & Healthy controls & Acromegalic & Healthy controls \\
\hline$N$ & 24 & 33 & 36 & 72 \\
\hline Age (years) & $48.1 \pm 13.4$ & $47.7 \pm 12.8$ & $55.4 \pm 12.3$ & $52.1 \pm 10.9$ \\
\hline Years since acromegaly diagnosis & $10.5 \pm 7.4$ & & $13.2 \pm 9.3$ & \\
\hline BMI $\left(\mathrm{kg} / \mathrm{m}^{2}\right)$ & $27.8 \pm 3.1$ & $26.6 \pm 2.9$ & $27.8 \pm 4$ & $27.1 \pm 5.8$ \\
\hline Waist circumference $(\mathrm{cm})$ & $104 \pm 10.5$ & $102.5 \pm 16.2$ & $92 \pm 11.4$ & $97.5 \pm 16.2$ \\
\hline GH levels $(\mu \mathrm{g} / \mathrm{l})$ & $2 \pm 2.8$ & & $2.1 \pm 14.9$ & \\
\hline$>1$ SDS & $0.6 \pm 2.5$ & & $-0.5 \pm 2.4$ & \\
\hline Total body mass (kg) & $89 \pm 13^{*}$ & $76.5 \pm 15.3^{*}$ & $70.8 \pm 12.8$ & $67.5 \pm 12.6$ \\
\hline Total fat mass (\%) & $23 . \overline{7} \pm 6.8$ & $25.9 \pm 4$ & $35.5 \pm 6.6$ & $36.5 \pm 6.6$ \\
\hline Trunk fat mass (\%) & $25.9 \pm 8.8$ & $28.3 \pm 7.5$ & $35.2 \pm 8.4$ & $35.9 \pm 8.6$ \\
\hline LBM (kg) & $64.6 \pm 8.7^{*}$ & $56.4 \pm 5.8^{*}$ & $42.1 \pm 9.3$ & $40.2 \pm 5.4$ \\
\hline $\mathrm{BMC}(\mathrm{kg})$ & $2.9 \pm 0.5^{\dagger}$ & $2.6 \pm 0.3^{\dagger}$ & $2.1 \pm 0.5$ & $2 \pm 0.3$ \\
\hline $\operatorname{BMD}\left(\mathrm{g} / \mathrm{cm}^{2}\right)$ & $1.21 \pm 0.1$ & $1.19 \pm 0.1$ & $1.11 \pm 0.2$ & $1.10 \pm 0.2$ \\
\hline
\end{tabular}

Data are expressed as mean \pm s.D. GH level: nadir GH post-oral glucose tolerance test or basal GH in patients on somatostatin analog treatment. IGF1 is expressed as SDS. BMI, body mass index; LBM, lean body mass; BMC, bone mineral content; BMD, bone mineral density. Significant difference between acromegalic and control men. ${ }^{\star} P<0.001,{ }^{\dagger} P<0.05$.

$(P<0.001)$, and BMC $(P<0.05)$ than controls. No differences in body mass index (BMI), waist circumference, or FM were observed between acromegalic patients and controls in either gender.

\section{Comparison of controlled and active acromegalic patients}

No differences in the prevalence of diabetes, hypertension, dyslipidemia, metabolic syndrome, or obesity were found between cured and active patients at the time of the study. In active disease, both males ( $n=10$; Table 2$)$ and females $(n=9$; Table 3$)$ had a decrease in total FM $(P<0.001$ and $P<0.01$ respectively $)$ and trunk FM $(P<0.001$ and $P<0.05$ respectively) when compared with controlled acromegaly and controls. Males (but not females) with active disease $(n=10)$ also had more LBM $(P<0.001)$ and BMC $(P<0.001)$, and a trend for more $\operatorname{BMD}(P=0.077)$ and total mass $(P=0.066)$ than controls. Males (Table 2) with controlled acromegaly $(n=14$; but not females; Table 3$)$ had more total mass $(P<0.05)$ and a trend to have more LBM $(P=0.065)$ than controls $(n=33)$. No differences in age, BMI, or waist circumference were seen between controlled and active acromegalic patients of both genders.

\section{Effect of gonadal function}

Since gonadal function is another determinant of $\mathrm{BC}$, the study groups were subdivided according to their gonadal status. Hypogonadal acromegalic women $(n=26 ; 23$ menopausal aged $>50$ years and 3 premenopausal, gonadotropin deficient) were older $(P<0.01)$, had a trend to have a greater waist circumference $(P=0.051)$, and more total and trunk FM $(P<0.01)$ than eugonadal patients $(n=10$; Table 4$)$. The same differences were found between hypogonadal ( $n=43$, all menopausal) and eugonadal $(n=20)$ control women. In contrast to female

Table 2 Clinical characteristics and body composition in acromegalic and control men.

\begin{tabular}{|c|c|c|c|c|}
\hline Men & Controlled acromegaly & Active acromegaly & Healthy controls & $\boldsymbol{P}$ \\
\hline$N$ & 14 & 10 & 33 & \\
\hline Age (years) & $51.9 \pm 11$ & $42.6 \pm 15$ & $47.7 \pm 12.8$ & NS \\
\hline Disease remission (years) & $9.4 \pm 6.3$ & - & - & \\
\hline Active disease duration (years) & $7.9 \pm 4.6$ & $15.9 \pm 12$ & - & NS \\
\hline BMI $\left(\mathrm{kg} / \mathrm{m}^{2}\right)$ & $27.7 \pm 3$ & $27.9 \pm 3.6$ & $26.6 \pm 2.9$ & NS \\
\hline Waist circumference $(\mathrm{cm})$ & $103.3+12.4$ & $104+9.6$ & $102.5+16.2$ & NS \\
\hline GH levels $(\mu \mathrm{g} / \mathrm{l})$ & $0.96 \pm 1.4$ & $3.5 \pm 3.8$ & & 0.057 \\
\hline IGF1 SDS & $-0.7 \pm 1.4$ & $2.5 \pm 2.5$ & & $<0.005$ \\
\hline Total mass $(\mathrm{kg})^{\star}$ & $89 \pm 1 \overline{4} .7$ & $89 \pm 11$ & $76.5 \pm 15.3$ & $<0.005$ \\
\hline Total fat mass $(\%)^{\dagger}$ & $27 \pm 6.2$ & $19.5 \pm 5.3$ & $25.9 \pm 4$ & $<0.001$ \\
\hline Trunk fat mass $(\%)^{\dagger}$ & $30 \pm 7.9$ & $20.6 \pm 7.2$ & $28.3 \pm 7.5$ & $<0.001$ \\
\hline LBM $(k g)^{\ddagger}$ & $61 . \overline{8} \pm 9.4$ & $68.1 \pm 6.8$ & $56.4 \pm 5.8$ & $<0.001$ \\
\hline $\mathrm{BMC}(\mathrm{kg})^{\S}$ & $2.7 \pm 0.4$ & $3.2 \pm 0.5$ & $2.6 \pm 0.3$ & $<0.005$ \\
\hline $\operatorname{BMD}\left(\mathrm{g} / \mathrm{cm}^{2}\right)$ & $1.16 \pm 0.1$ & $1.27 \pm 0.1$ & $1.19 \pm 0.1$ & 0.075 \\
\hline
\end{tabular}

Data are expressed as mean +s.D. GH level: nadir GH post-oral glucose tolerance test or basal GH in patients on somatostatin analog treatment. IGF1 is expressed as SDS. BMI, body mass index; LBM, lean body mass; BMC, bone mineral content; BMD, bone mineral density. ${ }^{*}$ Controlled patients had more total mass than controls $(P<0.05) .{ }^{\dagger}$ Active patients had less total and trunk FM than controlled patients and controls $\left(P<0.001\right.$ and $P<0.01$ respectively). ${ }^{\ddagger}$ Active patients had more LBM than controls $(P<0.001)$. ${ }^{\S}$ Active patients had more BMC than controlled acromegalic patients and controls $(P<0.01$ and $P<0.001$ respectively). 
Table 3 Clinical characteristics and body composition in acromegalic and control women.

\begin{tabular}{|c|c|c|c|c|}
\hline Women & Controlled acromegaly & Active acromegaly & Healthy controls & $\boldsymbol{P}$ \\
\hline$N$ & 27 & 9 & 72 & NS \\
\hline Age (years) & $57 \pm 12.4$ & $51.3 \pm 11$ & $52.1 \pm 10.9$ & NS \\
\hline Disease remission (years) & $13 . \overline{1} \pm 7.1$ & - & - & \\
\hline Active disease duration (years) & $7.9 \pm 4.8$ & $17 \pm 14.9$ & - & NS \\
\hline BMl $\left(\mathrm{kg} / \mathrm{m}^{2}\right)$ & $27 . \overline{7} \pm 3.5$ & $28 . \overline{1} \pm 5.6$ & $27.1 \pm 5.8$ & NS \\
\hline Waist circumference $(\mathrm{cm})$ & $93.4 \pm 12.3$ & $91.6 \pm 11.4$ & $97.5 \pm 16.2$ & NS \\
\hline GH levels $(\mu \mathrm{g} / \mathrm{l})$ & $0.8 \pm 0.7$ & $5.5 \pm 8.8$ & & $<0.05$ \\
\hline IGF1 SDS & $-1.2 \pm 1.9$ & $1.8 \pm 2.8$ & & $<0.05$ \\
\hline Total mass $(\mathrm{kg})$ & $72.2 \pm 12.7$ & $66.2 \pm 13$ & $67.5 \pm 12.6$ & NS \\
\hline Total fat mass $(\%)^{*}$ & $37.1 \pm 5.8$ & $30.3 \pm 6.7$ & $36.5 \pm 6.6$ & $<0.01$ \\
\hline Trunk fat mass $(\%)^{\dagger}$ & $37.5 \pm 7.1$ & $27.4 \pm 8.2$ & $35.9 \pm 8.6$ & $<0.05$ \\
\hline LBM $(\mathrm{kg})$ & $41.7 \pm 10$ & $43.5 \pm 7$ & $40.2 \pm 5.4$ & NS \\
\hline $\mathrm{BMC}(\mathrm{kg})$ & $2.1 \pm 0.3$ & $2.2 \pm 0.8$ & $2 \pm 0 . \overline{3}$ & NS \\
\hline $\mathrm{BMD}\left(\mathrm{q} / \mathrm{cm}^{2}\right)$ & $1.09+0.1$ & $1.17+0.3$ & $1.10+0.2$ & NS \\
\hline
\end{tabular}

Data are expressed as mean+s.D. GH level: nadir GH post-oral glucose tolerance test or basal GH in patients on somatostatin analog treatment. IGF1 is expressed as SDS. BMI, body mass index; LBM, lean body mass; BMC, bone mineral content; BMD, bone mineral density. *Active patients had less total FM than controlled and controls $(P<0.05)$. ${ }^{\dagger}$ Active patients had less trunk FM than controlled patients and controls $(P<0.005$ and $P<0.05$ respectively).

controls (where eugonadal subjects had more BMC than hypogonadal ones), no differences in BMC were found between eugonadal and hypogonadal acromegalic patients. No differences in age, BMI, waist circumference, or $\mathrm{BC}$ variables were found between active and controlled acromegalic hypogonadal women. In men, no differences were found in $\mathrm{BC}$ variables between eugonadal $(n=18)$ and hypogonadal $(n=6)$ acromegalic patients (total mass, FM, LBM, BMC, and BMD; data not shown). Comparison of gonadal status in healthy male controls was not possible, since only one male control was hypogonadal.

\section{Correlations with BC}

GH levels were negatively correlated with total and trunk FM in acromegalic men $(r-0.514$ and $r-0.490$; $P<0.05$ respectively) and women $(r-0.751$ and $r-0.778 ; P<0.001$ respectively). IGF1 was also negatively correlated with total and trunk FM in men ( $r-0.581$ and $r-0.538 ; P<0.01$ respectively) and women $(r-0.411$ and $r-0.390 ; P<0.05$ respectively). No other correlations were found in acromegalic patients and controls between BC variables and biochemical measurements analyzed (cholesterol, triglycerides, and glycemial; data not shown). After a stepwise, multiple linear regression analysis (which included total and trunk FM as the dependent variables, and years of disease, age, $\mathrm{GH}$, and IGF1 as independent variables), only GH in acromegalic females, and not other variables, predicted total FM $\left(r^{2}=0.686, \beta=-0.828, P<0.01\right)$ and trunk FM $\left(r^{2}=0.840, \beta=-0,840, P<0.01\right)$. This means that $68 \%$ of the variation of the total and $84 \%$ of the trunk FM were explained by GH. The acromegalic females were older than the males ( 55 vs 48 years, $P<0.05$ ), thus justifying including age in the linear regression analysis.

Table 4 Clinical characteristics and body composition in eugonadal versus hypogonadal acromegalic women and controls.

\begin{tabular}{|c|c|c|c|c|}
\hline & \multicolumn{2}{|c|}{ Acromegalic women } & \multicolumn{2}{|c|}{ Healthy control women } \\
\hline & Eugonadal & Hypogonadal & Eugonadal & Hypogonadal \\
\hline$N$ & 10 & 26 & 20 & 43 \\
\hline Controlled/active & $6 / 4$ & $21 / 5$ & - & - \\
\hline Disease remission (years) & $6.2 \pm 6.9^{\star}$ & $14.9 \pm 5.8^{*}$ & - & - \\
\hline Age (years) & $43 . \overline{3} \pm 7.3^{*}$ & $60.3 \pm 10.3^{*}$ & $39.7 \pm 7^{\dagger}$ & $59.4 \pm 7.5^{\dagger}$ \\
\hline $\mathrm{BMI}\left(\mathrm{kg} / \mathrm{m}^{2}\right)$ & $27.2 \pm 5.6$ & $28.1 \pm 3.4$ & $25.2 \pm 5.5$ & $28.1 \pm 6$ \\
\hline Waist circumference (cm) & $82.5 \pm 12$ & $95.1 \pm 10.8$ & $89.5 \pm 15.5^{\ddagger}$ & $102 . \overline{5} \pm 15.6^{\ddagger}$ \\
\hline GH levels $(\mu \mathrm{g} / \mathrm{l})$ & $2.1 \pm 1.7$ & $2.1 \pm 5.5$ & & \\
\hline IGF1 SDS & $0.4 \pm 3.3$ & $-0.9 \pm 1.9$ & & \\
\hline Total body mass (kg) & $66.4 \pm 13.3$ & $72.6 \pm 10.4$ & $66.3 \pm 13.4$ & $68.9 \pm 12.5$ \\
\hline Total fat mass (\%) & $30.4 \pm 6.8^{*}$ & $37.6 \pm 5.3^{*}$ & $33.3 \pm 6.3^{\ddagger}$ & $37.8 \pm 6.9^{\ddagger}$ \\
\hline Trunk fat mass (\%) & $29.3 \pm 9.6^{*}$ & $37.6 \pm 6.7^{*}$ & $31.9 \pm 8.3^{\ddagger}$ & $37.8 \pm 8.4^{\ddagger}$ \\
\hline LBM (kg) & $40.5 \pm 15.1$ & $42.8 \pm 5.7$ & $41.7 \pm 7.8$ & $40.3 \pm 4.9$ \\
\hline $\mathrm{BMC}(\mathrm{kg})$ & $2.2 \pm 0.3$ & $2.1 \pm 0.6$ & $2.2 \pm 0.3^{\ddagger}$ & $2 \pm 0.3^{\ddagger}$ \\
\hline BMD $\left(\mathrm{g} / \mathrm{cm}^{2}\right)$ & $1.12 \pm 1.1$ & $1.11 \pm 0.2$ & $1.11 \pm 0.2$ & $1.05 \pm 0.5$ \\
\hline
\end{tabular}

Data are expressed as mean +s.D. GH level: nadir GH post-oral glucose tolerance test or basal GH in patients on somatostatin analog treatment. IGF1 is expressed as SDS. BMI, body mass index; LBM, lean body mass; BMC, bone mineral content; BMD, bone mineral density. ${ }^{\star} P<0.01$ between eugonadal and hypogonadal acromegalic women; ${ }^{\dagger} P<0.01$ between eugonadal and hypogonadal healthy control women; ${ }^{\ddagger} P<0.05$ between eugonadal and hypogonadal healthy control women. No differences were found when eugonadal acromegalic patients and controls or hypogonadal acromegalic patients and controls were compared. 


\section{Discussion}

In this study, BC in acromegaly is compared with that of normal subjects, matched for age and sex. It is known that GH excess causes marked expansion of extracellular fluid volume, reduction in body FM, and increases LBM and BMD (6-9, 16-20). In both genders, when serum GH and IGF1 decrease after treatment, body weight falls over the first weeks due to a decrease in total body water, body cell mass, and LBM $(3,4,6,16)$. But in most of the studies, body weight returned to previous ranges, due to an increase in body FM, 3 months after hormonal normalization $(3,4,14,16,18)$.

To our knowledge, the long-term effect of acromegaly on $\mathrm{BC}$ has not been previously reported. In our study, no differences were found in BMI or waist circumference between acromegalic patients and healthy controls in either gender. Males with acromegaly (taking together those with controlled and active disease) had more total body mass, LBM, and BMC than control subjects, but no differences were found in FM (total and trunk). By contrast, no differences were found in $\mathrm{BC}$ variables between acromegalic females and control subjects, suggesting that excess GH/IGF1 affect BC in acromegalic males differently than in females.

Confirming previous studies $(3,9,14,19,20)$, active acromegaly was associated with less trunk and total FM than in controlled disease, in males and females. Moreover, this modification is reversible after disease control, since successfully treated males and females attain the same FM as that of controls. The reduction in FM in acromegaly is due to an inhibition of lipogenesis and stimulation of lipolysis caused by GH excess $(7,8$, 17). O'Sullivan et al. suggested that the increased energy expenditure observed in acromegaly could be another regulatory mechanism of FM; energy expenditure was reduced and FM increased as GH and IGF1 levels decreased with treatment (19).

Recent studies reported normal or increased bone mass in active acromegaly, but the effect of GH excess on BMD after hormonal normalization and possible gender differences remain unclear. During active acromegaly, it has been suggested that the anabolic effect of GH might be more pronounced in men, especially in cortical bone, with greater bone formation than resorption, regardless of gonadal function (21). In our study, active acromegalic male patients, but not females, showed more BMC and a trend for more BMD than controlled patients and normal subjects. A maintained anabolic effect of $\mathrm{GH}$ excess on BMD has been suggested to persist for a mean of 10 years after effective treatment of $\mathrm{GH}$ hypersecretion in males and females (22). Patients successfully treated for acromegaly maintained a BMD within or above the normal range (22) and the risk of peripheral fracture remained lower compared with controls (23).

The relationship between gonadal status and BMD in acromegaly has not been clearly established. An Italian study suggested that the anabolic effect of GH excess was sex independent in eugonadal patients with active acromegaly (24). Hypogonadism, which is relatively common in acromegaly, was reported to decrease BMD in active acromegaly compared with eugonadal patients or controls, especially in trabecular bone $(9,24-27)$. However, other studies did not confirm these findings (22, 28-30), since active acromegalic females did not have more BMC and BMD than healthy controls, as seen in males. This difference could be the result of the anabolic effect of $\mathrm{GH}$ on bone, on the one hand, and different exposure to gonadal steroids in both genders, on the other. Moreover, our data confirm that hypogonadal female control subjects had lower BMC than eugonadal women, but this difference was not found between hypogonadal and eugonadal acromegalic female patients. This may suggest that at least in acromegalic females, the anabolic effect of $\mathrm{GH}$ on bone may prevail over the lack of estrogens.

In most studies, an increase in LBM is found in active acromegaly, but again no gender differences have been reported $(1,6,7,9,31)$. GH hypersecretion has clear anabolic effects on protein synthesis in acromegaly. In our study, active acromegalic males had more LBM than normal male subjects, but these differences were not found in females. When controlled acromegalic male patients were compared with healthy controls, LBM and total mass remained higher in acromegalic patients, even when hormonal levels had been normal for over 9 years. This would suggest irreversible changes on lean body tissues in males induced by excessive GH and/or IGF1, which persist after endocrine normalization. This was not observed in females since active acromegalic women had similar LBM to healthy controls, indicating that GH acts differently on the LBM (which includes muscle, visceral organs, connective tissue, etc.) of males and females. This gender difference could be mediated by testosterone, which is known to enhance the metabolic effects of GH. Moreover, low-dose GH administration, which increases protein synthesis in healthy aged women and men, when co-administered with testosterone, only enhances this effect in elderly men, but not in women (32). Additionally, GH-deficient males are known to be more sensitive to treatment with rhGH and the response to GH of LBM varies with age, as demonstrated in GH-deficient patients treated with rhGH (33). In this study, the greatest increase in LBM was found in patients aged under 40 years, was less but still significant in 40- to 60-year-olds, and no effect was seen in patients over 60 years, even after 3 years of rhGH therapy. Our acromegalic females were older than the males; furthermore 8 out of $24(33 \%)$ of males were aged $<40$ years, while only 5 out of $36(14 \%)$ females were in this younger age range. Thus, we speculate that the lack of an effect of GH and IGF1 on LBM in females may be related to an age-specific LBM responsiveness to GH.

In our study, disease activity (IGF1 and GH levels) was correlated negatively with FM in men and women, but only in females did GH predict total and trunk FM in the 
stepwise, multiple linear regression analysis. This suggests a causal relationship between GH and FM in females, while in males other factors should explain the negative correlation observed, such as gonadal status, more active lifestyle, and a greater proportion of younger patients.

Estrogens are known to reduce lipid oxidation in normal and GH-deficient women and may contribute to the increase in body fat observed sometimes after oral estrogens (34). On the other hand, in healthy elderly males testosterone stimulates pulsatile and total $\mathrm{GH}$ production and thereby elevates IGF 1 concentrations (35) and reduces FM (36). Whether these effects of gonadal steroids also play a role in predicting FM in acromegaly is presently unclear.

As reported previously, acromegaly was associated with a higher prevalence of diabetes mellitus, hypertension, and metabolic syndrome than in the control population, features associated with an increased cardiovascular risk (37). The main cause of death in acromegaly is cardiovascular, most often cardiomyopathy or arrhythmias, but rarely ischemic heart disease. The changes in BC observed in acromegaly, especially the fall in body fat may contribute to explain this apparent paradox of less coronary disease despite more risk factors.

In conclusion, acromegaly induces considerable changes in $\mathrm{BC}$, which cannot be implied by simple anthropometry like BMI and waist circumference. DEXA appears to be a valid and useful tool in the assessment of $\mathrm{BC}$ in acromegaly. Changes in $\mathrm{BC}$ affect all three compartments studied. Regarding FM, a decrease was consistently found in active acromegaly in both men and women, reversible after disease control, since both males and females attain the same FM as controls. Regarding LBM, acromegaly did not induce any changes in females; in men, LBM and total body mass increased irreversibly, despite biochemical remission of acromegaly for over 9 years; thus, control of disease is not sufficient to normalize all variables of $\mathrm{BC}$. Regarding bone, acromegaly affected males and females differently; in males, active disease increased BMD and BMC, which normalized with disease control, but no effect of gonadal status was evidenced. In acromegalic females, neither activity nor hypogonadism seemed to affect BMD or $\mathrm{BMC}$, possibly as a result of the anabolic effect of $\mathrm{GH}$, on the one hand, and that of hypogonadism, on the other; thus, acromegaly may protect females from the effect of menopause on the bone.

\section{Declaration of interest}

There is no conflict of interest that could be perceived as prejudicing the impartiality of the research reported.

\section{Funding}

This work was supported by a grant from FIS 05/0448, Instituto Carlos III, Spain, and an unrestricted grant from Pfizer Endocrine Care, Spain.

\section{References}

1 Salomon F, Cuneo RC, Hesp R, Morris JF, Poston L \& Sonksen PH. Basal metabolic rate in adults with growth hormone deficiency and in patients with acromegaly: relationship with lean body mass, plasma insulin level and leukocyte sodium pump activity. Clinical Science 199283 325-330.

2 Brummer RJ, Bengtsson BA \& Bosaeus I. Validation of body composition determination by bioelectrical impedance analysis in acromegaly. European Journal of Clinical Nutrition 199246 47-52.

3 Bengtsson BA, Brummer RJ, Eden S, Bosaeus I \& Lindstedt G. Body composition in acromegaly: the effect of treatment. Clinical Endocrinology 198931 481-490.

4 Tominaga A, Arita K, Kurisu K, Uozumi T, Migita K, Eguchi K, IIda K, Kawamoto $\mathrm{H}$ \& Mizoue T. Effects of successful adenomectomy on body composition in acromegaly. Endocrine Journal 199845 335-342.

5 Brummer RJ, Lonn L, Bengtsson BA, Kvist H, Bosaeus I \& Sjostrom L. Comparison of different body composition models in acromegaly. Growth Regulation 19966 191-200.

6 Hansen TB, Gram J, Bjerre P, Hagen C \& Bollerslev J. Body composition in active acromegaly during treatment with octreotide: a double-blind, placebo-controlled cross-over study. Clinical Endocrinology 199441 323-329.

7 Rau H, Fischer H, Schmidt K, Lembcke B \& Althoff PH. Effect of bromocriptine withdrawal in acromegaly on body composition as assessed by bioelectrical impedance analysis. Acta Endocrinologica 1991125 273-279.

8 Goodman HM \& Grichting G. Growth hormone and lipolysis: a reevaluation. Endocrinology 1983113 1697-1702.

9 Kaji H, Sugimoto T, Nakaoka D, Okimura Y, Kaji H, Abe H \& Chihara K. Bone metabolism and body composition in Japanese patients with active acromegaly. Clinical Endocrinology 200155 $175-181$

10 Peiris AN, Sothmann MS, Hoffmann RG, Hennes MI, Wilson CR, Gustafson $\mathrm{AB}$ \& Kissebah $\mathrm{AH}$. Adiposity, fat distribution, and cardiovascular risk. Annals of Internal Medicine $1989 \mathbf{1 1 0}$ $867-872$.

11 Rader DJ. Effect of insulin resistance, dyslipidemia, and intraabdominal adiposity on the development of cardiovascular disease and diabetes mellitus. American Journal of Medicine $2007 \mathbf{1 2 0}$ (Suppl 1) S12-S18.

12 Kissebah AH. Intra-abdominal fat: is it a major factor in developing diabetes and coronary artery disease? Diabetes Research and Clinical Practice 199630 25-30.

13 Sironi AM, Pingitore A, Ghione S, De Marchi D, Scattini B, Positano V, Muscelli E, Ciociaro D, Lombardi M, Ferrannini E \& Gastaldelli A. Early hypertension is associated with reduced regional cardiac function, insulin resistance, epicardial, and visceral fat. Hypertension $2008 \mathbf{5 1} 282-288$.

14 Brummer RJ, Lonn L, Kvist H, Grangard U, Bengtsson BA \& Sjostrom L. Adipose tissue and muscle volume determination by computed tomography in acromegaly, before and 1 year after adenomectomy. European Journal of Clinical Investigation 199323 199-205.

15 Executive Summary of the Third Report of the National Cholesterol Education Program (NCEP). Expert panel on detection, evaluation, and treatment of high blood cholesterol in adults (adult treatment panel III). Journal of the American Medical Association 2001285 2486-2497.

16 Bengtsson BA, Brummer RJ, Eden S \& Bosaeus I. Body composition in acromegaly. Clinical Endocrinology 198930 121-130.

$17 \mathrm{Hu}$ HY, Yamamoto H, Sohmiya M, Abe T, Murakami Y \& Kato Y. Body composition assessed by bioelectrical impedance analysis (BIA) and the correlation with plasma insulin-like growth factor I (IGF-I) in normal Japanese subjects and patients with acromegaly and GH deficiency. Endocrine Journal 199441 63-69.

18 Bengtsson BA, Brummer RJ \& Bosaeus I. Growth hormone and body composition. Hormone Research 199033 (Suppl 4) 19-24. 
19 O'Sullivan AJ, Kelly JJ, Hoffman DM, Freund J \& Ho KK. Body composition and energy expenditure in acromegaly. Journal of Clinical Endocrinology and Metabolism 199478 381-386.

20 Bolanowski M, Milewicz A, Bidzinska B, Jedrzejuk D, Daroszewski J \& Mikulski E. Serum leptin levels in acromegaly - a significant role for adipose tissue and fasting insulin/glucose ratio. Medical Science Monitor 20028 CR685-CR689.

21 Bolanowski M, Wielgus W, Milewicz A \& Marciniak R. Axial bone mineral density in patients with acromegaly. Academic Radiology $20007592-594$.

22 Biermasz NR, Hamdy NA, Pereira AM, Romijn JA \& Roelfsema F. Long-term maintenance of the anabolic effects of $\mathrm{GH}$ on the skeleton in successfully treated patients with acromegaly. European Journal of Endocrinology 2005152 53-60.

23 Vestergaard P \& Mosekilde L. Fracture risk is decreased in acromegaly - a potential benefit effect of growth hormone. Osteoporosis International 200415 155-159.

24 Scillitani A, Battista C, Chiodini I, Carnevale V, Fusilli S, Ciccarelli E, Terzolo M, Oppizzi G, Arosio M, Gasperi M, Arnaldi G, Colao A, Baldelli R, Ghiggi MR, Gaia D, Di Somma C, Trischitta V \& Liuzzi A. Bone mineral density in acromegaly: the effect of gender, disease activity and gonadal status. Clinical Endocrinology $2003 \mathbf{5 8}$ 725-731.

25 Dimaraki EV, Symons KV \& Barkan AL. Raloxifene decreases serum IGF-I in male patients with active acromegaly. European Journal of Endocrinology $2004 \mathbf{1 5 0} 481-487$.

26 Lesse GP, Fraser WD, Farquharson R, Hipkin L \& Vora JP. Gonadal status is an important determinant of bone density in acromegaly. Clinical Endocrinology $1998 \mathbf{4 8} 59-65$.

27 Scillitani A, Chiodini I, Carnevale V, Giannatempo GM, Frusciante V, Villella M, Pileri M, Guglielmi G, Di Giorgio A, Modoni S, Fusilli S, Di Cerbo A \& Liuzzi A. Skeletal involvement in female acromegalic subjects: the effects of growth hormone excess in amenorrheal and menstruating patients. Journal of Bone and Mineral Research 199712 1729-1736.

28 Ho PJ, Fig LM, Barkan AL \& Shapiro B. Bone mineral density of the axial skeleton in acromegaly. Journal of Nuclear Medicine 199233 1608-1612.

29 Kayath MJ \& Vieira JG. Osteopenia occurs in a minority of patients with acromegaly and is predominant in the spine. Osteoporosis International 19977 226-230.
30 Diamond T, Nery L \& Posen S. Spinal and peripheral bone mineral densities in acromegaly: the effects of excess growth hormone and hypogonadism. Annals of Internal Medicine 1989111 567-573.

31 Landin K, Petruson B, Jakobsson KE \& Bengtsson BA. Skeletal muscle sodium and potassium changes after successful surgery in acromegaly: relation to body composition, blood glucose, plasma insulin and blood pressure. Acta Endocrinologica $1993 \mathbf{1 2 8}$ 418-422.

32 Huang X, Blackman MR, Herreman K, Pabst KM, Harman SM \& Caballero B. Effects of growth hormone and/or sex steroid administration on whole-body protein turnover in healthy aged women and men. Metabolism 200554 1162-1167.

33 Attanasio AF, Bates PC, Ho KK, Webb SM, Ross RJ, Strasburger CJ, Bouillon R, Crowe B, Selander K, Valle D \& Lamberts SW. Hypopituitary Control and Complications Study International Advisory Board. Human growth hormone replacement in adult hypopituitary patients: long-term effects on body composition and lipid status - 3-year results from the HypoCCS database. Journal of Clinical Endocrinology and Metabolism 200287 1600-1606.

34 Leung KC, Johannsson G, Leong GM \& Ho KKY. Estrogen regulation of growth hormone action. Endocrine Reviews 2004 25 693-721.

35 Veldhuis JD, Keenan DM, Mielke K, Miles JM \& Bowers CY. Testosterone supplementation in healthy older men drives $\mathrm{GH}$ and IGF-I secretion without potentiating peptidyl secretagogue efficacy. European Journal of Endocrinology 2005153 577-586.

36 Allan AC, Struss JG, Burger HG, Forbes EA \& McLachlan RI. Testosterone therapy prevents gain in visceral adipose tissue and loss of skeletal muscle in nonobese aging men. Journal of Clinical Endocrinology and Metabolism 200893 139-146.

37 Mestrón A, Webb SM, Astorga R, Benito P, Catalá M, Gaztambide S, Gómez JM, Halperín I, Lucas-Morante T, Moreno B, Obiols G, de Pablos P, Páramo C, Picó A, Torres E, Varela C, Vázquez JA, Zamora J, Gilabert M \& for all the participants in REA. Epidemiology, clinical characteristics, outcome, morbidity and mortality in acromegaly based on the Spanish Acromegaly Registry (REGISTRO ESPAÑOL DE ACROMEGALIA -REA-). European Journal of Endocrinology 2004151 439-446.

Received 4 September 2008

Accepted 17 September 2008 